\title{
Debt Finance among Vietnamese Enterprises: The Influence of Managers' Gender
}

\author{
Hoang Lan $\mathrm{HO}^{1}$, Minh Hoa DAO ${ }^{2}$, The Cong PHAN ${ }^{3}$
}

Received: May 18, 2020 Revised: July 19, 2020 Accepted: August 10, 2020

\begin{abstract}
This paper examines the impact of gender on access to debt finance among Vietnamese enterprises. The paper investigates data and variables retrieved from the World Bank Enterprise Survey dataset using five Probit models. The regression results suggest that there exist more unfavourable debt financing conditions for women-led firms (WLF), measured as a lower probability of having loan applications fully approved. Firm's age, working sector, and perception of access to finance as a difficulty are found to have explanatory power on the discrimination. More importantly, the perception of debt finance as a difficulty or firms' level of confidence significantly explains the variance of the dependent variable of probability of loan approval, or gender effect would be more pronounced if the firm already has a low level of confidence. The paper also contributes in testing for the gender effect on Vietnamese enterprises from different sectors and scale, unlike other prior research papers focusing on specific sectors and/or small and medium enterprises only. The findings are highly useful for Vietnamese credit institutions to set out a specific business policy to attract more WLFs and help promoting gender equality in the working environment, especially in debt financing, which is often neglected in existing regulation and policy frameworks.
\end{abstract}

Keywords: Debt Finance, Gender Influence, Probit Model, Vietnam

JEL Classification Code: G40, J16, L25

\section{Introduction}

A recent factsheet from International Finance Corporation (2018) implied that challenges in the business environment, especially in financing, still persist for businesswomen. For instance, half of the country's labour force is working in small- and medium-sized businesses, but these firms are facing a $\$ 1.2$ billion financing gap for women-led firms. There are several studies on the influence of gender on accessibility to debt finance in Vietnam; however, most of them are conducted with a narrow scope and lack a view of

${ }^{1}$ First Author and Corresponding Author. Lecturer, International School of Management and Economics, National Economics University, Vietnam [Postal Address: 207 Giai Phong Road, Dong Tam Ward, Hai Ba Trung District, Hanoi, 113068, Vietnam] Email: ho.lan@isneu.org ${ }^{2}$ Bank for Investment and Development of Vietnam Securities Joint Stock Company, Vietnam. Email: daominhhoa1712@gmail.com ${ }^{3}$ Department of Economics, Thuongmai University, Vietnam. Email: congpt@tmu.edu.vn

(c) Copyright: The Author(s)

This is an Open Access article distributed under the terms of the Creative Commons Attribution Non-Commercial License (https://creativecommons.org/licenses/by-nc/4.0/) which permits unrestricted non-commercial use, distribution, and reproduction in any medium, provided the original work is properly cited. the whole economy (Oanh, 2010; Rand, 2007). This research explores whether a gender-gap exists in debt finance accessibility among all types of Vietnamese enterprises using the World Bank Enterprise Surveys (WBES) dataset.

There are different approaches applied in this topic. Researchers differentiate between demand-side factors evolving from behaviors of the firm's owner and supply-side factors resulting from behaviors of lenders. The demandside factors, also known as statistical discrimination, can be explained by dissimilarities between women-led firms (WLFs) and men-led firms (MLFs) in terms of firm's characteristics, which are age, size, sales, owner's education level, and so on. In contrast, the supply-side factors, also called taste-based discrimination, result from the fact that lenders may treat loan applications differently simply based on the gender of the applicant regardless of similar characteristics between WLFs and MLFs (Piras, Presbitero \& Rabellotti, 2013). Some other studies explore the relationship between business managers' gender and debt finance regarding the volume of loans, terms of credit, and probability of the loan application being granted (Carter, Shaw, Lam \& Wilson, 2007). This paper focuses on demand-side factors as well as their component factors, aiming to answer the following research questions: 
1. Are there any differences in accessing debt finance between male- and female-led businesses in Vietnam?

2. Do WLFs face more or less credit rationing compared to MLFs?

The research questions are examined by a quantitative analysis investigating the WBES dataset using probit regression models. The paper is constructed as follows: Section 2 reviews different strands of literature and states the hypotheses of the paper; Section 3 describes the methodology and data collection process; Section 4 presents important results from analyzing the data; Section 5 discusses the main findings and suggests some policy recommendations.

\section{Literature Review}

\subsection{Access to Debt Finance}

Access to finance is often measured by three components, including access to bank loans, credit rationing, and discouragement from loan application. Access to bank loans is frequently described by a binary variable identifying if the enterprise has a line of credit from a banks, or other financial institution, or not (Phan, 2018). Coleman (2000) investigated the influence on the availability of various credit products, for instance financial leases, commercial mortgages, motor vehicle loans, equipment loans, and so on by several variables of firm's characteristics such as age, size of business, gender of the owner, type of organization, and sector in which the enterprise was working. The same approach of measuring access to bank loans was used in the papers of Khoi, Nartea, Gan and Cohen (2013) and Le (2012). Other papers employed numerical proxies for access to bank loans, for example ratio of bank loans to total capital (Le \& Nguyen, 2009) and the amount of short-term and long-term debt retrieved from firms' annual reports (Alenka \& Igor, 2012). Regarding credit rationing, loan rejection rate or approval rate is often employed. Access to credit was intensively investigated and proxied by a binary variable with the relationship of it and owner's characteristics, firm attributes, and characteristics of the credit line (Asiedu, Freeman, \& Nti-Addae, 2012).

It is worth noting that many papers use a combination of both, the first and the second approach. By combining the two approaches into a complex matrix, Kuntchev, Ramalho, Rodríguez-Meza, and Yang (2012) generated a categorical dependent variable dividing credit constraint into four groups, namely (i) fully credit-constrained, (ii) partiallycredit constrained, (iii) maybe-credit constrained, and (iv) non-credit constrained, and used an ordered probit regression model to examine the dependent variable.

The investigation on firms' discouragement from loan application was emphasized by Muravyev, Talavera, and Schäfer (2009) as a compensation for underestimating discrimination when employing the second approach. This approach is rather dependent on the perception of the firm's owners; therefore, it is common to see this indicator being studied in categorical forms (Mascia \& Rossi, 2017).

This study focuses on the second approach, especially the probability of approval rate conditioned by firms who are already loan applicants. For this reason, access to debt finance can be understood as having at least one loan application which is fully approved.

\subsection{Gender Effect}

\subsubsection{WLFs Face More Difficulties Accessing Debt Finance}

The first strand of literature assessing the gender effect in access to finance indicates that WLFs face higher requirements when applying for debt finance. Coleman (2000) found statistical evidence of financial discrimination against WLFs because of the common characteristic of their enterprises. Particularly, WLFs are younger, have lower sales, fewer employees, engage more in service businesses, and have about $10 \%$ lower use of bank loans, which is similar to the conclusion of among exporting firms. This explanation results in a 7\% lower loan approval rate, higher amount of interest paid among US WLFs (Coleman, 2000) and 13\% higher of loan rejection rate among exporting WLFs (Asiedu, Freeman, $\&$ Willson, 2012). Higher rejection rates among WLFs can also be explained by the pattern that WLFs are less likely to apply for a loan since they tend to anticipate being rejected more than MLFs (Moro, Wisniewski, \& Mantovani, 2017). The same result was found among European SMEs (Mascia \& Rossi, 2017), among Vietnamese manufacturing firms (Rand, 2007), in a study among bank loan officers (Carter, Shaw, Lam \& Wilson, 2007) and with European manufacturing firms (Alenka \& Igor, 2012), in the papers of Piras, Presbitero and Rabellotti (2013) and Muravyev, Talavera, and Schäfer (2009).

Among papers that conclude a more unfavourable lending environment exists for WLFs, Constantinidis, Cornet, and Asandei (2006) released a paper which emphasizes the homogeneity factor. The homogeneity factor implies that WLFs are discriminated against, not because of a gender effect, but in terms of corporate characteristics. This discrimination is distinguishable for each WLF, since each firm has distinctive characteristics, unlike the explanations of Coleman (2000) and Asiedu, Freeman and Willson (2012) that treat WLFs as a homogeneous group sharing the same characteristics that lead to higher credit rationing. Particularly, the findings of Constantinidis, Cornet, and Asandei (2006) indicate that among all WLFs, retailers and service firms or firms with lower owners' educational levels and social position are more credit rationed but it seems that WLFs do not face difficulties while accessing finance if they operate in male dominated sectors. 


\subsubsection{WLFs Have Easier Access to Debt Finance}

The second strand of literature explains the pattern where WLFs are less discriminated in access to finance. Focusing on the impact of race, ethnicity, and gender, Asiedu, Freeman and Willson (2012) found an insignificant difference between white business women and white business men in the denial rate, but a lower interest rate of about 0.71 percentage points for white WLFs. Likewise, Kuntchev, Ramalho, RodríguezMeza, and Yang (2012) came up with the result that femalemanaged and -owned firms located in the Asia Pacific region have a lower probability of facing higher levels of credit constraint, compared to male-owned and -managed firms, which is similar to the conclusion of Aggarwal and Goodell (2014). Thus, it is hypothesized that:

\section{H1: WLFs have a lower probability of loan approval}

\subsection{Firm's Characteristics Variables}

\subsubsection{Firm Age}

A significant amount of prior research has empirically proved that longer established firms, often correlating with more experience in the capital market and deeper relationship with lenders, tend to have a higher probability of getting a loan (Le, 2012; Thanh, Cuong, Dung, \& Chieu, 2011). However, Rand (2007) concluded a negative statistically significant coefficient $(-0.004)$ of the firm age variable and the probability of holding debt among 594 Vietnamese manufacturing firms and further explained that older firms tend to be more settled and less innovative, thus requiring less external finance. By employing both the normal form and the squared form of the firm age variable, Piras, Presbitero and Rabellotti (2013) came up with a solution for this controversial debate. Their paper implied that, before their maturity phase, firms often require more capital and their creditworthiness improves over years. Then, this trend tends to slow down or terminate when firms step into the decline phase. Therefore, it is hypothesized that:

H2: The probability of loan approval increases as firms grow older, but gradually diminishes at some point in the future life-cycle of the firm.

\subsubsection{Firm Sales}

Previous research describes a common trend that the higher the sales of the enterprise, the greater the access to finance. Coleman (2000) is among the most prominent researchers in this field, concluded in a paper strong, positive relationships between firm sales and accessibility to five major credit products. A similar relationship is found for the probability of debt holding and Vietnamese family businesses' revenue, in which a one unit increase in revenue leads to an increase of 0.093 of the probit regression z-score (Rand, 2007). The same pattern was found among exporting firms, together with statistically significant, negative coefficients of -3.35 and -2.59 of firm sales and two Tobit models for rejection rates, implying that firms with higher sales are less likely to be credit rationed (DiCaprio, Yao, $\&$ Simms, 2017). Because of higher sales tend to generate higher trust of lenders for firms paying back debts, the third hypothesis is:

H3: Firms with higher sales have a higher probability of loan approval.

\subsubsection{Firm Size}

It is a common pattern among previous studies that lenders prefer lending to big companies over small- and medium-sized firms because, if the firm already operated with a large scope of permanent employment, it probably would generate higher profitability leading to a higher certainty of on-time repayment (Coleman, 2000). Similarly, Vietnamese SMEs, especially micro-size firms, cannot avoid this common trait of being more credit-rationed, which is their natural characteristic and one of the main reason for loan denial (Thanh, Cuong, Dung, \& Chieu, 2011). Considering a greater scope including all firm sizes, Piras, Presbitero and Rabellotti (2013) and Muravyev, Talavera, and Schäfer (2009) used the number of employees as a proxy for firm size and came up with the same result. The former paper concluded negative coefficients for the influence of firm size on credit rationing while the later saw significant, positive coefficients of 0.096 and 0.016 for the impact of firm size on probability of loan approval. For that reason, the fourth hypothesis is:

H4: Larger firms (in terms of number of employees) have a higher probability of loan approval.

\subsubsection{Sector Bias}

Sector is another prominent firm characteristic that receives much attention. The effect of sector on access to bank loans yields distinguishable results depending on how the variable sector is employed. Using the sector variable as a control tool, Mascia and Rossi (2017) found no significant spread in the amount of credit constraint between manufacturing and wholesale/retail firm, which is similar to the result of for agricultural manufacturers and wholesalers working in the suburban areas of Hanoi. For that reason, the fifth and the sixth hypotheses are as follows: 


\section{H5: Manufacturing firms have a higher probability of loan approval \\ H6: Women-led manufacturing firms have higher accessibility to debt finance than women-led services and retail firms.}

\subsubsection{Working Experience}

Business owners' experiences have been shown to have an inverse relationship with their loan rejection rate (Thanh, Cuong, Dung, \& Chieu, 2011). Particularly, for business owners with at least 20 years of experience, all loan requests were accepted, whereas the number of loans accepted reduces continuously as a business owner's experience declines.

When working experience is treated as an indicator to study the comparative impact between WLFs and MLFs in access to finance, the result is not favourable for WLFs. The finding in the paper by Carter, Shaw, Lam and Wilson (2007), generated from the perspective of 35 bank loan officers participating in focus groups, implied that WLFs are more likely to be assessed by their knowledge of the business than MLFs. Considered with sectoral biasness, women tend to have greater experience in retail and service fields, which plays a major role in their choice in entrepreneurship but indirectly leads to the fact that they are more credit-rationed (Constantinidis, Cornet, \& Asandei, 2006).

H7: Managers with more working experience have a higher probability of loan approval

\subsubsection{Financial-Related Variables}

The more confident the owner or top manager of the firm is in their business ability, the lower the difficulty in their perception towards access to finance. Prior research has empirically shown that the higher amounts of confidence associate with easier access to finance (Alenka \& Igor, 2012). Additionally, DiCaprio, Yao and Simms (2017) observed that business women are more prone to think that access to finance is a major obstacle than business men.

H8: Firms with higher collateral value have a higher probability of loan approval

H9: Firms with overdraft facility have a higher probability of loan approval

H10: Firms with the perception that access to finance is an obstacle have a higher probability of loan approval.

\section{Methodology}

Data for the study were drawn from the 2015 Vietnamese Enterprise Surveys conducted by the World Bank Group in collaboration with the General Statistics Office of Vietnam. This study solely focuses on the gender effect among Vietnamese corporate loan applicants. From the questionnaire responses of 996 enterprises, the chosen sample includes 290 firms that fulfill two major criteria, namely: (i) the enterprise has applied for a line of credit or a loan in the most recent fiscal year and (ii) the enterprise has a valid answer on the gender variable.

The probit model is chosen to investigate the relationship between the consequences of loan application and the explanatory variables. The probit regression model takes the following form:

$$
\operatorname{Pr}\left(D_{\mathrm{i}}=1\right)=\phi\left(\alpha+\beta_{1} G_{\mathrm{i}}+\beta_{2} C_{\mathrm{i}}+\beta_{3} F_{\mathrm{i}}+\beta_{4} I_{\mathrm{i}}+\varepsilon_{\mathrm{t}}\right)
$$

in which: $i$ stands for businesses, $\phi$ denotes the cumulative density function of a normal distribution.

$\mathrm{D}_{\mathrm{i}}$ is the dependent dichotomous variable, taking the value of one if the loan application is fully approved, zero otherwise, according to the definition of rejection/approval rate in prior research (Le \& Taegi, 2020; DiCaprio, Yao, \& Simms, 2017; Asiedu, Freeman, \& Willson, 2012; Thanh, Cuong, Dung, \& Chieu, 2011; Muravyev, Talavera, \& Schäfer, 2009; Oanh, 2010; Rand, 2007). The dependent variable, probability of loan approval, is generated from an original categorical variable with four possible values, which are: (i) application was approved in full, (ii) application was approved in part, (iii) application was rejected, and (iv) application was withdrawn.

$G_{\mathrm{i}}$ stands for the gender variable. The gender of the firm is determined by the gender of the top manager (Mascia \& Rossi, 2017; Piras, Presbitero, \& Rabellotti, 2013; Sauer $\&$ Wiesemeyer, 2018). The binary gender variable Female Manager takes the value of one if the top manager of the firm is female, and zero otherwise.

$C_{\mathrm{i}}$ is a set of firm characteristics used as control variables, including age, square of age, size, logarithm of sales, sector, and years of working experience of the owner, from the methodology of previous papers (Coleman, 2000; DiCaprio, Yao, \& Simms, 2017; Le \& Nguyen, 2009; Mascia \& Rossi, 2017; Moro, Wisniewski, \& Mantovani, 2017).

$L_{\mathrm{i}}$ denotes a set of finance-related characteristics, namely the requirement of overdraft facility and the logarithm of the collateral value. $I_{\mathrm{i}}$ is the interaction term between the opinion of the firm towards access to finance and the gender variable. Appendix provides a list of employed variables as well as their descriptions.

Since a unit change in an independent variable in the probit regression model doesn't correlate with a unit change in the dependent variable, but a change in the maximum likelihood that the dependent variable equals to one, the probit regression model can be difficult to interpret. Furthermore, the marginal effect of an independent variable on the dependent variable is not constant. Therefore, the marginal effect of each independent variable is calculated, 
with the condition that other independent variables are held at their mean values.

Muravyev, Talavera, and Schäfer (2009) raised awareness to the issue of sample selection. This issue arises because the majority of research in this field neglects non-applicant firms, who choose not to apply for credit in anticipation of the probability that their application will be rejected or of unfavourable loan requirements being offered due to discrimination. However, the sample including nonapplicants can help to investigate if there is gender-based or firm-based discrimination among discouraged firms. Therefore, a probit regression model of discouragement is run (model (5)) and compared to the result of the main model. In order to identify the issue of gender effect persisting in different operating sectors, two separate probit models are employed for a sample of only manufacturing firms (model (2)) and another of only service firms (model (3)).

\section{Empirical Results}

\subsection{Descriptive Statistics}

Out of 290 sample enterprises, 48 firms had their most recent loan rejected, while 242 firms had their loan application fully approved; 240 firms are managed by males, 50 firms are led by females (see Table 1).

Both rejected and approved groups consisted of about $33.4 \%$ of large firms and $66.6 \%$ of small and medium firms. In terms of operating sectors, the approved group consisted of $70.25 \%$ manufacturers, $3.3 \%$ higher than that of rejected firms, whereas the rejected group consisted more of service firms than the approved group. Both the approved and rejected group have a higher proportion of enterprises with no overdraft. However, the approved group has more firms with overdraft facilities, particularly $13.22 \%$, nearly $59 \%$ higher than the rejected group's $8.33 \%$. Interestingly, the rejected group was recorded with the perception of higher levels of difficulty for access to finance. For example, $4.17 \%$ of the rejected group are firms who considered access to finance as a very severe difficulty, while the approved group was perceived lower levels of difficulty (see Table 2).

Firms with female top managers accounted for only $17.24 \%$ while those with male top managers accounted for $82.76 \%$ of the 290 enterprises. There was a slight difference in the percentage of firms having their application approved between the two groups, particularly, $88 \%$ of firms having female top managers had their loans application fully accepted, whereas the male group had only $82.50 \%$ approved.

Table 1: Descriptive statistics by results of loan applications and gender of firms managers

\begin{tabular}{|c|c|c|c|c|}
\hline Characteristics / Variables & MLFs & WLFs & Fully, partially rejected & Fully approved \\
\hline \multicolumn{5}{|l|}{ Mean statistics } \\
\hline Age of firm (years) & 32 & 15 & 58 & 24 \\
\hline Log of sales (VND) & 23.94 & 23.40 & 23.87 & 23.84 \\
\hline Log of collateral value (VND) & 22.72 & 22.35 & 22.83 & 22.63 \\
\hline Manager experience (years) & 17 & 17 & 17 & 17 \\
\hline \multicolumn{5}{|l|}{ Descriptive statistics (\%) } \\
\hline MLFs (240 firms) & & & 17.50 & 82.50 \\
\hline WLFs (50 firms) & & & 12.00 & 88.00 \\
\hline Fully, partially rejected & 87.50 & 12.50 & & \\
\hline Fully approved & 81.82 & 18.18 & & \\
\hline Manufacturing & 70.42 & 66.00 & 66.67 & 70.25 \\
\hline Retail services & 4.58 & 6.00 & 2.08 & 5.37 \\
\hline Other services & 25.00 & 28.00 & 31.25 & 24.38 \\
\hline SMEs & 63.75 & 80.00 & 66.67 & 66.53 \\
\hline Large enterprises & 36.25 & 20.00 & 33.33 & 33.47 \\
\hline No overdraft facilities & 87.92 & 86.00 & 91.67 & 86.78 \\
\hline Have overdraft facilities & 12.08 & 14.00 & 8.33 & 13.22 \\
\hline
\end{tabular}

Table 2: Proportion of opinion towards access to finance by loan application results

\begin{tabular}{|l|c|c|c|c|c|}
\hline$\%$ & No difficulty & Minor difficulty & Moderate difficulty & Major difficulty & Very severe difficulty \\
\hline Fully, partially rejected & 20.83 & 10.42 & 39.58 & 25.00 & 4.17 \\
\hline Fully approved & 42.98 & 32.23 & 16.12 & 8.26 & 0.41 \\
\hline
\end{tabular}


Large enterprises accounted for $20 \%$ of the female group, less than the male group with $36.25 \%$. On the other hand, the female group consisted of $14 \%$ of firms with overdraft facilities, slightly higher than the $12.08 \%$ of the male group. In terms of sectors in which firms were working, the proportions between two groups are not really different, with approximately $65-70 \%$ manufacturers and $30-35 \%$ service firms.
The difficulty levels that firms perceived of access to finance are overall similar between the two groups. However, one interesting pattern is that $38 \%$ female firms regarded access to finance as a minor obstacle, $12 \%$ higher than that of male firms. For the other categories, the percentages in the female group are slightly lower than the male group, but the spread is not significant (see Table 3).

Table 3: Proportion of opinion towards access to finance by gender of the manager of the firm

\begin{tabular}{|l|c|c|c|c|c|}
\hline$\%$ & No difficulty & Minor difficulty & Moderate difficulty & Major difficulty & Very severe difficulty \\
\hline MLFs & 40.42 & 26.67 & 20.42 & 11.25 & 1.25 \\
\hline WLFs & 34.00 & 38.00 & 18.00 & 10.00 & 0.00 \\
\hline
\end{tabular}

Table 4: Regression results

\begin{tabular}{|c|c|c|c|c|c|}
\hline \multirow{2}{*}{ Variables } & \multicolumn{4}{|c|}{ Probability of Loan Approval } & \multirow{2}{*}{$\begin{array}{c}\text { Discouraged } \\
(5)\end{array}$} \\
\hline & (1) & (2) & (3) & (4) & \\
\hline Female Manager & $-1.239^{* *}$ & -0.787 & -1.165 & $-1.433^{* *}$ & 1.105 \\
\hline Retail services & 0.391 & & & 0.411 & -0.404 \\
\hline Other services & -0.0935 & & & -0.0557 & 0.381 \\
\hline Age & -0.000350 & -0.000112 & -0.0178 & -0.000275 & -0.0663 \\
\hline Log of firm $a^{2} e^{2}$ & -0.0238 & -0.0812 & -0.0619 & -0.00722 & 0.647 \\
\hline Large firms & 0.177 & 0.101 & -0.101 & 0.163 & 0.703 \\
\hline Log of sales & -0.0819 & 0.0275 & -0.140 & -0.0671 & -0.139 \\
\hline Manager experience & 0.000227 & 0.0172 & -0.0509 & -0.00114 & $-0.0513^{* *}$ \\
\hline Overdraft facilities & 0.0885 & 0.589 & -0.0246 & 0.139 & -0.422 \\
\hline Log of collateral value & 0.000191 & -0.101 & -0.0245 & -0.0155 & 0.153 \\
\hline Based outcome: No difficulty \& Male & 0 & 0 & 0 & 0 & 0 \\
\hline No difficulty \& Female & 1.015 & 0.565 & (omitted) & 0.911 & $-1.642^{*}$ \\
\hline Minor difficulty \& Male & 0.111 & 0.384 & -0.804 & 0.103 & -0.288 \\
\hline Minor difficulty \& Female & $1.390^{*}$ & 0.727 & (empty) & $1.574^{\star \star}$ & -0.986 \\
\hline Moderate difficulty \& Male & $-1.133^{* * *}$ & $-1.018^{* * *}$ & $-1.773^{* * *}$ & $-1.127^{* * *}$ & -0.410 \\
\hline Moderate difficulty \& Female & 1.036 & 0.505 & (empty) & 1.260 & (omitted) \\
\hline Major difficulty \& Male & $-1.061^{* * *}$ & $-0.911^{* *}$ & $-1.893^{* *}$ & $-1.015^{\star * *}$ & (empty) \\
\hline Major difficulty \& Female & (omitted) & (omitted) & (empty) & (omitted) & (empty) \\
\hline Very severe difficulty \& Male & $-1.821^{* *}$ & (empty) & (empty) & $-1.978^{\star * *}$ & (empty) \\
\hline Very severe difficulty \& Female & (empty) & (empty) & (empty) & (empty) & (empty) \\
\hline Constant & $3.455^{*}$ & 3.094 & 7.254 & & -2.503 \\
\hline Constant cut 1 & & & & $-4.530^{* * *}$ & \\
\hline Constant cut 2 & & & & $-3.397^{* *}$ & \\
\hline Observations & 290 & 200 & 65 & 290 & 81 \\
\hline Pseudo R-squared & 0.1596 & 0.1651 & 0.2803 & 0.1434 & 0.1679 \\
\hline $\mathrm{P}>$ Chi-squared & $0.0008^{* * *}$ & $0.0146^{\star *}$ & $0.0614^{*}$ & $0.0004^{* * *}$ & 0.3642 \\
\hline
\end{tabular}

Standard errors: ${ }^{* * *}: p<0.01,{ }^{* *}: p<0.05,{ }^{*}: p<0.1$. Variables with omitted labels are automatically removed from the regression result because of collinearity. 


\subsection{Regression Analysis}

Regression results of all five models are presented in Table 4. Model 1 is the main probit model with the probability of loan approval as the dependent variable. Model 2 and 3 are developed from Model 1, but for firms working in manufacturing and non-retail service sectors, respectively. Model 4 is an ordered probit model, which regresses the same set of dependent and independent variables as Model 1 does. Model 5 is carried out to solve the issue of sample selection by regressing the discouraged variable with the same set of independent variables (see Table 4).

Overall, WLFs had a lower probability of having their loan applications fully accepted than men-managed firms, as the coefficients of the gender variable are consistently negative in all models. Only two coefficients in the main probit model and the ordered probit model is significant at the $95 \%$ confidence level, and the strongest effect is observed in the ordered model, with the coefficient equal to -1.165 . All of the coefficients except for gender are statistically insignificant. Therefore, this may require further investigation on a better dataset.

As for the interaction term between the level of difficulty and gender of the top manager, values of all subcategories are compared to the value of the base outcome which is MLFs perceiving no difficulty towards access to finance. With the same level of no difficulty, firms with female top managers are more likely to officially acquire bank loans than those with male top managers. However, the result is not statistically significant. Interestingly, the same pattern is observed for minor difficulty level, since the coefficient of female-managed firms is 1.390 , significant at $10 \%$ and higher than the coefficient of male-managed firms at 0.111. Logically, higher levels of difficulty are associated with the lower probability of officially receiving bank loans. However, this relationship is recorded for male firms only.

\subsection{Marginal Effects}

Marginal effects for the two statistically significant variables, which are Female Manager and Opinions towards access to debt finance are calculated in Table 5 to plot the relationship of each of these variable to the probability of the dependent variable in each probit model equals to one. This is done while holding other variables at their mean value in order to annul the inconsistent change in one unit of an independent variable to the change in the dependent variable in the probit regression model.

The marginal effects for female-managed firms are unpredictable and inconsistent in the first three models. Conversely, in Model 5, the marginal effect for femalemanaged firms is 0.301 , significant at $0.01 \%$, higher than the coefficient 0.246 of male firms. This result indicates that being a firm with female top manager results in a probability of $30 \%$ of being discouraged from accessing finance, while the probability among the male group is only $24.6 \%$, if other characteristics are held at their means.

Table 5: Marginal effects at means of probit models

\begin{tabular}{|l|c|c|c|c|}
\hline \multirow{2}{*}{ Variables } & \multicolumn{2}{|c|}{ Probability of Loan Approval } & Discouraged \\
\cline { 2 - 5 } & $\mathbf{( 1 )}$ & $\mathbf{( 2 )}$ & $\mathbf{( 3 )}$ & $\mathbf{( 5 )}$ \\
\hline Male Top Manager & $0.829^{* * *}$ & $0.846^{* * *}$ & $0.800^{* * *}$ & $0.246^{* * *}$ \\
\hline Female Top Manager & - & $0.859^{* * *}$ & - & $0.301^{* * *}$ \\
\hline No difficulty \& Male & $0.921^{* * *}$ & $0.913^{* * *}$ & $0.960^{* * *}$ & $0.289^{* * *}$ \\
\hline No difficulty \& Female & $0.884^{* * *}$ & $0.874^{* * *}$ & $0.770^{* * *}$ & $0.154^{*}$ \\
\hline Minor difficulty \& Male & $0.936^{* * *}$ & $0.958^{* * *}$ & $0.854^{* * *}$ & $0.211^{* *}$ \\
\hline Minor difficulty \& Female & $0.941^{* * *}$ & $0.903^{* * *}$ & - & 0.325 \\
\hline Moderate difficulty \& Male & $0.618^{* * *}$ & $0.648^{* * *}$ & $0.582^{* * *}$ & 0.182 \\
\hline Moderate difficulty \& Female & $0.888^{* * *}$ & $0.861^{* * *}$ & - & $0.647^{* * *}$ \\
\hline Major difficulty \& Male & $0.644^{* * *}$ & $0.685^{* * *}$ & $0.540^{* * *}$ & - \\
\hline Major difficulty \& Female & $0.577^{* * *}$ & $0.726^{* * *}$ & - & - \\
\hline Very severe difficulty \& Male & $0.352^{* * *}$ & - & - & - \\
\hline Very severe difficulty \& Female & - & - & - & - \\
\hline Observations & 290 & 200 & 65 & 81 \\
\hline
\end{tabular}

Note: (-) is unpredictable marginal effect 
By looking at the marginal effects of interaction terms, the differences between male and female groups are more pronounced. Lower probability for the female group compared to male group is observed in no difficulty, moderate difficulty and major difficulty levels, which indicates that women-managed firms in these groups have lower accessibility to finance. On average, both male and female groups show that the lower the difficulty level, which means the higher the confidence of the borrower, the higher the accessibility of finance and all relationships are statistically significant at $1 \%$ (see Table 5).

\subsection{Explanatory Power of the Models}

Model 3 conducted among only service firms explains the largest variance of the dependent variable. Among three models $(1,4$, and 5) conducted with the same set of independent variables, Model 5 shows the strongest explanation power while Model 4 using ordered probit regression is the weakest. However, in terms of the overall significance of the models, Model 5 describing the determinants of discouragement is not statistically significant even at $10 \%$, whereas Models 1 and 4, explaining the influences on probability of approval, show high statistical significance.

\section{Discussion and Recommendations}

\subsection{Gender Effect}

The first pattern observed is that WLFs and MLFs do not dramatically differ from each other in terms of the number of approved loans. From the descriptive statistics, the proportion of WLFs having fully approved loans is $88 \%$, just slightly higher than $82.50 \%$ among MLFs. This can be explained by the fact that WLFs do not face more discouragement on bank finance than man, so there tendency to have and equal number of approved loans among WLFs and MLFs. On the other hand, WLFs can sometimes have preferences towards the choice of borrowing from relatives or acquaintances because of social conceptions. However, this pattern is minor and needs further examination.

The second result arising from the econometric models implies an opposite conclusion to the above result. In Models 1 and 4, WLFs have a negative correlation with favourable borrowing outcomes, the coefficients are significant at $5 \%$ for both probit and ordered probit models, while other characteristics remain the same between the two groups. This result indicates taste-based discrimination, which is loan results are determined differently among firms because of the gender of the top manager, exists among sampled Vietnamese enterprises. Taste-based gender discrimination can be seen among male lenders, since they often form judgement about the ability of female borrowers merely based on their physical characteristics and social prejudices. These findings support for the hypothesis $\mathrm{H} 1$ and are in agreement with previous findings (Asiedu, Freeman, \& Willson, 2012; Coleman, 2000; Moro, Wisniewski, \& Mantovani, 2017).

Thirdly, from regression results, lenders do decide different loan results between WLFs and MLFs, but the decision is based on the nature of the firm rather than the gender characteristic. In terms of sector, although the result is not statistically significant, regression Models 2 and 3 may imply that WLFs working in the service sector have a lower probability of fully approved loans than WLFs in manufacturing sector. This result does not only prove a distinctive level barrier to access of debt finance between the two sectors from the same gender of the top manager, but also shows that Vietnamese WLFs are not a homogeneous group. Though both are led by women, manufacturing firms are likely to receive more favourable preferences than service firms. There maybe a reason for that.

Because of a distinctive entrepreneurship decision commonly seen among WLFs, business-women often choose to establish a service company more than a manufacturing company. This leads to the fact that WLFs are generally smaller in size, so they are less attractive to lenders, and service firms have lower demand for external finance. Hence, women-led service firms should have a lower probability of loan approval. Descriptive statistics also suggested that there were a larger number of male-led than female-led big firms, more male-led than female-led manufacturing firms, and fewer male-led than female-led service firms. Overall, it can be conclude that the WLFs are discriminated partially because of their firm characteristics, the choice of sector and firm size, but these characteristics are not exactly the same among every female-led firm, and operating in fields with more masculinity such as manufacturing industries can benefit WLFs by raising their probability of loan approval. This finding not only supports both hypotheses H5 and H6 but also shows great similarity to previous research (Constantinidis, Cornet, \& Asandei, 2006).

Fourthly, one of the most significant contributions of this paper is to take into account an interaction term between the variable of difficulty level of debt finance and the gender variable in the regression model. While previous papers (Coleman, 2000) add interaction terms between the variables of firm age, size, sales, and corporation types with the gender indicator, it would be inefficient because the variables of age, size, and sales show weak explanatory power for the variance of the dependent variable in this paper. The finding which is interesting and significant is that in the moderate and major difficulty level, WLFs have a lower probability of loan approval than MLFs do. In other words, the gender effect can be more pronounced if the firm already has a low level of confidence. The reason is probably because WLFs can be more risk-averse, according to the data retrieved 
from the third interviewee. From this finding, the statistical discrimination is proved again, which is WLFs are more restricted from fully receiving bank loans because of their common lower level of confidence compared with MLFs. The negative relationship between level of confidence and loan results is also supported by regression results.

\subsection{Recommendations}

Gender discrimination in workplace is prohibited in Vietnamese legal documents. The Labour Code of Vietnam ("Labor Code," 2012) requires employers to "ensure gender equality and promote gender equality in recruitment, employment, training, working hours, break time, wages and in other conditions." Furthermore, the Law on Gender Equality ("Law on Gender Equality," 2006) strengthened that businesswomen and businessmen must not be discriminated against in terms of recruitment, wages, bonuses, social insurance, working condition, training and promotion. Gender equality in the workplace is a major objective of the National Strategy of Gender Equality for 2011-2020. In terms of international regulations, Vietnam joined both the Convention C100 of Equal Pay (International Labor Organization, 2017a) and Convention C111 on Discrimination (International Labor Organization, 2017b) in 1997.

It can be seen that the policy framework for gender equality in the workplace is available. However, it is possible that due to the rapid growth in the number of SMEs, these policies are not fully implemented and obeyed in Vietnam. It is considered that proposing a more favourable lending policy for WLFs is not practical. Therefore, new policies should focus on mitigating statistical discrimination. One suggestion is to supervise the lending process more closely so that the transparency and creditability are preserved; hence, the gender effect should be lowered compared to the influences of other firm characteristics. Another recommendation is for researchers and social activists. The unfavourable borrowing results for WLFs do not only indicate inefficiency of the Vietnamese economy and financial market, but also implies low levels of financial inclusion for Vietnamese WLFs. More researches should be focused on this topic to raise the awareness of gender discrimination in accessing finance. The awareness can be raised through workshops or conferences for WLFs, especially for female entrepreneurs so that business-women should be acknowledge about their disadvantage and together find more practical solutions.

\section{Conclusion}

The research paper has applied five econometric models to test for the significance of difference in accessibility to debt finance among Vietnamese enterprises based on gender of the top manager. Overall, the results imply that the gender effect exists and influenced the outcomes of loan applications among Vietnamese enterprises in 2015. The quantitative results indicate that, even when firm characteristics are controlled for, taste-based gender discrimination exists in loan outcomes. Further investigations prove the co-existence of statistical discrimination since different borrowing outcomes between WLFs and MLFs are also the result of firm characteristics, especially firm age, sector, and the level of difficulty that debt finance is considered. Other determinants, namely firm sales, size, experience of the top manager, collateral value, and overdraft facility, support for the hypotheses but insignificantly explain the variance of the dependent variable.

The findings of this paper are bounded by some limitations. The dataset was carried out in five distinctive regions across Vietnam. Each has different financial patterns and distinctive industry characteristics, which could explain many statistically insignificant quantitative relationships. Another limitation is that, due to data limitation as well as the problem of reducing the degrees of freedom, the paper has to drop some additional specific determinants such as relationship lending, political connection, and social position of the borrower that might impact the accessibility to debt finance of firms.

The research paper makes a major contribution in testing for the gender effect on Vietnamese enterprises from all sectors and scale, unlike other prior research papers focusing on specific sectors and/or SMEs only. The results of the paper are highly useful for Vietnamese credit institutions to set out a specified business strategy to attract more WLFs. By this way, the paper can contribute in promoting gender equality in the working environment, especially in firms' financial decisions, which is often neglected in existing regulation and policy frameworks.

\section{References}

Aggarwal, R., \& Goodell, J. W. (2014). Cross-national differences in access to finance: Influence of culture and institutional environments. Research in International Business and Finance, 31, 193-211. http://dx.doi.org/10.1016/j.ribaf.2013.09.004.

Alenka, S., \& Igor, P. (2012). The influence of entrepreneur's characteristics on small manufacturing firm debt financing. Journal for East European Management Studies, 17(1), 104-130. https://www.jstor.org/stable/23281745

Asiedu, E., Freeman, J. A., \& Nti-Addae, A. (2012). Access to Credit by Small Businesses: How Relevant Are Race, Ethnicity, and Gender? American Economic Review, 102(3), 532-537. DOI: $10.1257 /$ aer.102.3.532

Carter, S., Shaw, E., Lam, W., \& Wilson, F. (2007). Gender, entrepreneurship, and bank lending: The criteria and processes used by bank loan officers in assessing applications. 
Entrepreneurship Theory and Practice, 31(3), 427-444. https:// doi.org/10.1111/j.1540-6520.2007.00181.x

Coleman, S. (2000). Access to capital and terms of credit: A comparison of men- and women-owned small businesses. Journal of Small Business Management, 38(3), 37-52.

Constantinidis, C., Cornet, A., \& Asandei, S. (2006). Financing of women-owned ventures: The impact of gender and other owner-and firm-related variables. Venture Capital, 8(2), 133-157. http://dx.doi.org/10.1080/13691060600572557

DiCaprio, A., Yao, Y., \& Simms, R. (2017). Women and trade: Gender's impact on trade finance and Fintech. ADBI Working Paper Series. Retrieved December 5, 2019 from: https://www. adb.org/publications/women-and-trade-gender-impact-tradefinanceand-fintech

International Finance Corporation. (2018). Increasing Opportunities for Women in Vietnam: Key facts and challenges. Washington, DC: World Bank Group.

International Labor Organization. (2017a). Ratifications of C100 - Equal Remuneration Convention, 1951 (No. 100). Retrieved December 5, 2019, from: https:/www.ilo.org/dyn/normlex/en/f?p =1000:11300:0::NO:11300:P11300_INSTRUMENT_ID:312245

International Labor Organization. (2017b). Ratifications of C111 - Discrimination (Employment and Occupation) Convention, 1958 (No. 111). Retrieved December 5, 2019, from: https:// www.ilo.org/dyn/normlex/en/f?p=1000:11300:0::NO:11300 :P11300_INSTRUMENT_ID:312256

Khoi, P. D., Nartea, G. V., Gan, C., \& Cohen, D. A. (2013). Determinants of accessibility to formal and informal credit in the Mekong River Delta. Journal of Science of Can Tho University, 28, 38-53. DOI: 10.1016/j.asieco.2013.02.003

Kuntchev, V., Ramalho, R., Rodríguez-Meza, J., \& Yang, J. S. (2012). What have we learned from the Enterprise Surveys regarding access to finance by SMEs? Enterprise Analysis Unit of the Finance and Private Sector Development, The World Bank Group, Washington, DC. https://doi.org/10.1596/18139450-6670

Labor Code. (2012). Retrieved October 5, 2019, from: https://www. ilo.org/dyn/natlex/natlex4.detail?p_isn=91650\&p_lang=en

Law on Gender Equality. (2006). Retrieved December 5, 2019, from: https://www.ilo.org/dyn/natlex/natlex4.detail?p_isn=76089\&p_ lang=en

Le, N. T. B., \& Nguyen, T. V. (2009). The Impact of Networking on Bank Financing: The Case of Small and Medium-Sized Enterprises in Vietnam. Entrepreneurship Theory and Practice, 33(4), 867-887. https://journals.sagepub.com/doi/abs/10.1111/ j.1540-6520.2009.00330.x
Le, P. N. M. (2012). What determines the access to credit by SMEs? A case study in Vietnam. Journal of Management Research, 4(4), 90-115. DOI: 10.5296/jmr.v4i4.1838

Le, A. H., \& Taegi, K. I. M. (2020). The Effects of Economic Freedom on Firm Investment in Vietnam. Journal of Asian Finance, Economics and Business, 7(3), 9-15. https://doi. org/10.13106/jafeb.2020.vol7.no3.9

Mascia, D. V., \& Rossi, S. P. S. (2017). Is There a Gender Effect on the Cost of Bank Financing? Journal of Financial Stability, 31(August), 136-153. DOI: 10.1016/j.jfs.2017.07.002

Moro, A., Wisniewski, T. P., \& Mantovani, G. M. (2017). Does a manager's gender matter when accessing credit? Evidence from European data. Journal of Banking \& Finance, 80, 119-134. http://dx.doi.org/10.1016/j.jbankfin.2017.04.009

Muravyev, A., Talavera, O., \& Schäfer, D. (2009). Entrepreneurs' gender and financial constraints: Evidence from international data. Journal of Comparative Economics, 37(2), 270-286. DOI:10.1016/j.jce.2008.12.001

Oanh, N. Q. (2010). Farming Household's Access to Formal Credit: Case of Study in Suburban of Hanoi. Journal of Science and Development, 8(1), 170-177.

Piras, C., Presbitero, A. F., \& Rabellotti, R. (2013). Definitions Matter: Measuring Gender Gaps in Firms'Access to Credit. Washington, DC: Inter-American Development Bank. Available at: https://www.researchgate.net/profile/Roberta_Rabellotti/ publication/263809810_Definitions_Matter_Measuring Gender_Gaps_in_Firms'_Access_to_Credit_Inter-American Development_Bank/links/0c96053̈bf0ae51b1_d9000000.pdf

Phan, T. L. (2018). The Relationship between Perceived Access to Finance and Social Entrepreneurship Intentions among University Students in Vietnam. Journal of Asian Finance, Economics and Business, 5(1), 63-72. http://dx.doi.org/10.13106/jafeb.2018. vol5.no1.63

Rand, J. (2007). Credit constraints and determinants of the cost of capital in Vietnamese manufacturing. Small Business Economics, 29(1-2), 1-13. DOI: 10.1007/s11187-005-1161-2

Sauer, R. M., \& Wiesemeyer, K. H. (2018). Entrepreneurship and gender: differential access to finance and divergent business value. Oxford Review of Economic Policy, 34(4), 584-596. DOI: $10.1093 /$ oxrep/gry017

Thanh, V. T., Cuong, T. T., Dung, B. V., \& Chieu, T. D. (2011). Small and Medium Enterprises Access to Finance in Vietnam. Small and Medium Enterprises Access to Finance in Selected East Asian Economies. [Report]. Retrieved December 5, 2019 from: https:/www.eria.org/uploads/media/Research-Project-Report/ RPR_FY2010_14_Chapter_6.pdf 
Appendix: Explanation of the variables

\begin{tabular}{|c|c|c|}
\hline Variables & Type and Description & Original variables \\
\hline \multicolumn{3}{|c|}{ Dependent variables } \\
\hline $\begin{array}{l}\text { Probability of loan } \\
\text { approval }\end{array}$ & $\begin{array}{l}\text { Binary [1 - if most recent applied loan is fully } \\
\text { approved, } 0 \text { - otherwise] }\end{array}$ & $\begin{array}{l}\text { Results of the most recent loan, categorical } \\
\text { [1-fully rejected, 2-approved in part, 3-fully } \\
\text { approved] }\end{array}$ \\
\hline Discouraged & $\begin{array}{l}\text { Binary [ } 1 \text { - if firms is discouraged from access to } \\
\text { finance, } 0 \text { - firms already have sufficient capital } \\
\text { and are not discouraged from access to finance }\end{array}$ & $\begin{array}{l}\text { Reasons for not applying for a loan, categorical [1 } \\
\text { - Have sufficient capital, } 2 \text { - Complex application } \\
\text { procedures, } 3 \text { - Not favourable interest rates, } 4 \text { - } \\
\text { Too high collateral requirements, } 5 \text { - Insufficient } \\
\text { size of loan and maturity, } 6 \text { - did not think it would } \\
\text { be approved }\end{array}$ \\
\hline \multicolumn{3}{|c|}{ Independent variables } \\
\hline $\begin{array}{l}\text { Female top } \\
\text { manager }\end{array}$ & $\begin{array}{l}\text { Binary [ } 1 \text { - if the top manager of the firm is } \\
\text { female, } 0 \text { - otherwise] }\end{array}$ & $\begin{array}{l}\text { Is the top manager female, categorical }[1-\text { Yes, } \\
2-\mathrm{No}]\end{array}$ \\
\hline Sector & $\begin{array}{l}\text { Categorical [ } 1 \text { - Manufacturing, } 2 \text { - Retail } \\
\text { services, } 3 \text { - Other services] }\end{array}$ & The same \\
\hline Age & Continuous, age of the firm & $\begin{array}{l}\text { Continuous, in what year this establishment } \\
\text { formally registered }\end{array}$ \\
\hline $\log$ of age ${ }^{2}$ & $\begin{array}{l}\text { Continuous, logarithm form of squared of the } \\
\text { firm's age }\end{array}$ & \\
\hline Large firms & $\begin{array}{l}\text { Binary [ } 1 \text { - Large firms (100 employees or more, } \\
0 \text { - Small and medium firms (Fewer than } 100 \\
\text { employees) }\end{array}$ & $\begin{array}{l}\text { Firm size, categorical [1 - Small, } 2 \text { - Medium, } \\
3 \text { - Large] }\end{array}$ \\
\hline Log of sales & Continuous, logarithm form of sales & $\begin{array}{l}\text { Continuous, firm's total sales of all products and } \\
\text { services in the last fiscal year }\end{array}$ \\
\hline $\begin{array}{l}\text { Manager } \\
\text { experience }\end{array}$ & $\begin{array}{l}\text { Continuous, years of experience of the top } \\
\text { manager in the sector }\end{array}$ & The same \\
\hline Overdraft facilities & $\begin{array}{l}\text { Binary [ } 1 \text { - Firm has an overdraft facility, } \\
0 \text { - otherwise] }\end{array}$ & $\begin{array}{l}\text { Categorical [1 - Firm has an overdraft facility, } \\
2 \text { - Firm does not have an overdraft facilities] }\end{array}$ \\
\hline Difficulty & $\begin{array}{l}\text { Categorical, the level of access to finance as } \\
\text { an difficulty of the firm [0-no difficulty, 1-minor } \\
\text { difficulty, 2-moderate difficulty, 3-major difficulty, } \\
\text { 4-very severe difficulty] }\end{array}$ & The same \\
\hline
\end{tabular}

